\title{
Effects of comonomer with carboxylic group on stabilization of high molecular weight polyacrylonitrile nanofibrous copolymers
}

\author{
Danyun Lei ${ }^{1}$, Kesavan Devarayan ${ }^{1}$, Xiang-Dan Li $^{2}$, Woong-Ki Choi ${ }^{3}$, Min-Kang Seo ${ }^{3}$ and Byoung-Suhk Kim, ${ }^{1,4,}$ \\ ${ }^{1}$ Departments of BIN Fusion Technology, Chonbuk National University, Jeonju 561-756, Korea \\ ${ }^{2}$ Key Laboratory of Catalysis and Materials Science, The State Ethnic Affairs Commission \& Ministry of Education, South-Central \\ University for Nationalities, Wuhan, Hubei, 430074, PR China \\ ${ }^{3}$ R\&D Division, Korea Institute of Carbon Convergence Technology, Jeonju 561-844, Korea \\ ${ }^{4}$ Departments of Organic Materials and Fiber Engineering, Chonbuk National University, Jeonju 561-756, Korea
}

\section{Article Info \\ Received 6 September 2014 \\ Accepted 5 October 2014 \\ *Corresponding Author \\ E-mail: kbsuhk@jbnu.ac.kr \\ Tel: $+82-63-270-2352$}

\section{Open Access}

DOI: http://dx.doi.org/

10.5714/CL.2014.15.4.290

This is an Open Access article distributed under the terms of the Creative Commons Attribution Non-Commercial License (http://creativecommons.org/licenses/ by-nc/3.0/) which permits unrestricted non-commercial use, distribution, and reproduction in any medium, provided the original work is properly cited.

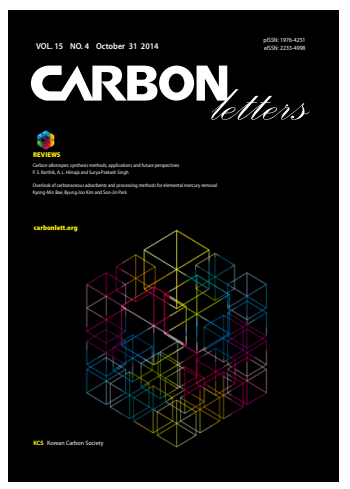

http://carbonlett.org

pISSN: 1976-4251

eISSN: 2233-4998

Copyright $\odot$ Korean Carbon Society

\begin{abstract}
New precursors, poly(acrylonitrile-co-crotonic acid) (poly(AN-CA)) and poly(acrylonitrileco-itaconic acid-co-crotonic acid) (poly(AN-IA-CA)) copolymers, for the preparation of carbon fibers, were explored in this study. The effects of comonomers with acidic groups, such as crotonic acid (CA) and/or itaconic acid (IA), on the stabilization of nanofibrous polyacrylonitrile (PAN) copolymers were studied. The extent of stabilization, evaluated by Fourier transform infrared spectroscopy, revealed that the CA comonomer could retard/control the stabilization rate of PAN, in contrast to the IA comonomer, which accelerated the stabilization process. Moreover, the synthesized PAN copolymers containing CA possessed higher Mv than those of the IA copolymers and also showed outstanding dimension stability of nanofibers during the stabilization, which may be a useful property for improving the dimensional stability of polymer composites during manufacturing.
\end{abstract}

Key words: carbon nanofibers, carbon precursor, electrospinning, polyacrylonitrile

\section{Introduction}

Carbon fibers are finding increased uses in a variety of applications because of their high tensile strength and modulus combined with their light weight, which make these fibers attractive for high volume applications ranging from sporting goods to aircraft structures [1]. It is well known that carbon fiber can be made from various precursors, such as polyacrylonitrile (PAN), rayon, pitch, etc., for industrial production at present [2]. Among these materials, PAN-based precursors are preferable since the resulting carbon fibers have relatively high strength and elongation, and have very low volume fraction of voids [3-5]. However, the use of pristine PAN homopolymer is restricted due to its low spinnability and stabilization [6,7]. An important strategy to improve the processability of pristine PAN is to incorporate small amounts of comonomers containing a carboxyl group, such as acrylic acid (AA), itaconic acid (IA), or methacrylic acid (MAA) into PAN during polymerization. The use of acidic comonomers is indeed preferable for significant reduction of the initiation temperature of cyclization; such addition also promotes the stabilization of PAN. In this study, we have evaluated PAN copolymers containing crotonic acid (CA), a structural analog of MAA, as new precursors for carbon fiber; these new materials are compared with PAN homopolymer and poly(AN-IA) copolymer as controls. The effects of carboxylic acid on the stabilization of PAN copolymers were examined. The synthesized PAN homopolymer, poly(AN-IA), poly(AN-CA), and poly(AN-IA-CA) copolymers were electrospun into fine fibers; this process was followed by stabilization. Structural evaluation was performed by Fourier transform infrared spectroscopy (FT-IR), thermogravimetric analysis (TGA), and X-ray diffraction (XRD) analysis. 


\section{Experimental}

\subsection{Synthesis of PAN homopolymer and poly (AN-CA), poly(AN-IA), poly(AN-IA-CA) copolymers}

PAN homopolymer and poly(AN-IA), poly(AN-CA), poly(AN-IA-CA) copolymers were prepared using a conventional free-radical polymerization technique. Briefly, $3.92 \mathrm{~g}$ of acrylonitrile (AN) (98.0 wt \%), $0.08 \mathrm{~g}$ of CA (2.0 wt \%), and 12.4 $\mathrm{mg}$ of azobisisobutyronitrile (AIBN, $0.2 \mathrm{~mol} \%$ of monomers), were stirred in $16 \mathrm{~g}$ of dimethyl sulfoxide (DMSO) under nitrogen atmosphere at room temperature for $30 \mathrm{~min}$ followed by reflux at $60^{\circ} \mathrm{C}$ for $24 \mathrm{~h}$. The synthesized poly(AN-CA) copolymer was precipitated in deionized water, and then washed with deionized water and methanol in sequence. The solid product was recovered by filtration and dried under vacuum at $40^{\circ} \mathrm{C}$ for 24 h. Similarly, poly(AN-IA) copolymer was also synthesized. In the case of poly(AN-IA-CA), the total comonomer concentrations of IA $\left(f_{I A}\right)$ and CA $\left(f_{C A}\right)$ were controlled to be ca. $2.0 \mathrm{wt} \%$. Each comonomer was kept at a concentration of $1.0 \mathrm{wt} \%$. PAN homopolymer was synthesized using a similar procedure in the absence of comonomers.

PAN: Yield, 64.0\%. ${ }^{1} \mathrm{H}$ nuclear magnetic resonance (NMR) $\left(400 \mathrm{MHz}, \mathrm{DMSO}-\mathrm{d}_{6}\right): \delta 1.94-2.24 \mathrm{ppm}\left(2 \mathrm{H},-\mathrm{CH}_{2}\right), 3.04-3.29$ ppm $(1 \mathrm{H},-\mathrm{CH})$.

Poly(AN-IA) copolymer: Yield: 70.4\%. ${ }^{1} \mathrm{H}$ NMR (400 MHz, DMSO-d $\left.{ }_{6}\right): 1.94-2.23 \mathrm{ppm}\left(-\mathrm{CH}_{2}\right.$ of AN and IA), 3.04-3.27 ppm $(1 \mathrm{H},-\mathrm{CH})$.

Poly(AN-CA) copolymer: Yield: 70.0\%. ${ }^{1} \mathrm{H}$ NMR (400 MHz, DMSO-d $\left.{ }_{6}\right): \delta 1.39 \mathrm{ppm}\left(-\mathrm{CH}_{3}\right.$ of CA), $1.95-2.25 \mathrm{ppm}\left(-\mathrm{CH}_{2}\right.$ of $\mathrm{AN}$ and IA), 3.03-3.27 ppm (1H, $-\mathrm{CH})$.

Poly(AN-IA-CA) copolymer: Yield: $70.0 \%$. ${ }^{1} \mathrm{H}$ NMR (400 $\left.\mathrm{MHz}, \mathrm{DMSO}-\mathrm{d}_{6}\right): \delta 1.39 \mathrm{ppm}\left(-\mathrm{CH}_{3}\right.$ of CA $), 1.95-2.23 \mathrm{ppm}(2 \mathrm{H}$, $-\mathrm{CH}_{2}$ of $\mathrm{AN}$ and IA), 3.05-3.27 ppm (1H, $\left.-\mathrm{CH}\right)$.

\subsection{Stabilization of electrospun PAN homo- polymer and its copolymer nanofibers}

All the synthesized polymers were dissolved in DMF under magnetic stirring with a polymer content of $9.0 \mathrm{wt} \%$. The solution was supplied through a $10-\mathrm{mL}$ syringe having a plastic tip with an inner diameter of $0.6 \mathrm{~mm}$. Electrospinning [8] was carried out at $8 \mathrm{kV}$ using a NanoNC power supply with a tip-to-collector distance of $15 \mathrm{~cm}$ at about $23^{\circ} \mathrm{C}-27^{\circ} \mathrm{C}$ and relative humidity of $45 \%-55 \%$. The electrospun fibers were collected on an aluminum foil and dried under vacuum at room temperature. The stabilizations of the electrospun PAN homo- and copolymer nanofibers were performed by increasing from room temperature to $280^{\circ} \mathrm{C}$ at a heating rate of $1.0^{\circ} \mathrm{C} / \mathrm{min}$; samples were kept at $280^{\circ} \mathrm{C}$ for $1 \mathrm{~h}$ under aerobic condition $[9,13]$.

\subsection{Characterization}

The Ubbelohde viscometry method was used to measure the viscosity average molecular weight $\left(M_{v}\right)$ of the synthesized PAN homopolymer and its copolymers at $25 \pm 0.1{ }^{\circ} \mathrm{C} . M_{v}$ was calculated with the following Eq. (1) [10].

$$
[\eta]=2.33 \times 10^{-4} \times\left[M_{v}\right]^{0.75}
$$

where $[\eta]$ is the intrinsic viscosity obtained by extrapolating the concentration-reduced viscosity plot to zero concentration.

The synthesized polymers were characterized by ${ }^{1} \mathrm{H}$ NMR spectroscopy (FT-NMR, JNM-EX400, $400 \mathrm{MHz}$ ) in DMSO-d solvent. The morphologies of the as-spun and stabilized nanofibers were observed under a JEOL JSM-5900 scanning electron microscope (SEM) after sputtering the samples with platinum for $120 \mathrm{~s}$. Thermogravimetric analyses (TGA) were conducted from room temperature to $800^{\circ} \mathrm{C}$ using a TA Q600 at a heating rate of $10^{\circ} \mathrm{C} / \mathrm{min}$. XRD patterns were recorded on a Rikaku X-ray diffractometer ( $\mathrm{Cu} \mathrm{K}_{\alpha}$ radiation) with a scanning rate of $4 \% \mathrm{~min}$.

\section{Results and Discussion}

Poly(AN-CA) and poly(AN-IA-CA) copolymers containing $\mathrm{CA}$ as a new precursor for carbon fiber were synthesized by solution polymerization technique. The experimental conditions and characteristics of the synthesized polymers are summarized in Table 1. It was noteworthy that the PAN copolymers containing CA synthesized in this study showed higher $M_{v}$ than those synthesized in earlier reports using other comonomers such as methyl acrylate (MA) and IA [11,12], suggesting that the presence of CA comonomer accelerated the growth of polymer chains, leading to higher molecular weight. So far, the large diameter of the polymer fibers has been one of the limitations of carbon fiber strength. In order to achieve uniform heat treatment, fibers must have a small diameter. Thus, a small diameter can reduce any gradient temperature across the fibers in order to obtain uniformity of heat treatment. Fig. 1 presents SEM images of electrospun PAN homopolymer and poly(AN-IA), poly(AN-CA), poly(AN-IA-CA) copolymer nanofibers, which were electrospun from $9.0 \mathrm{wt} \%$ solution, before Fig. 1(A) and after Fig. 1(B) stabilization at $280^{\circ} \mathrm{C}$ for $1 \mathrm{~h}$. All the polymers were successfully electrospun to produce nanofibers with the diameters ranging from $470 \pm 50 \mathrm{~nm}$ to $860 \pm 80 \mathrm{~nm}$. As can be seen in Fig. 1a, all the fibers were homogeneous. In particu-

Table 1. Synthesis and characteristics of PAN homopolymer, and poly(AN-IA), poly(AN-CA), poly(AN-IA-CA) copolymers

\begin{tabular}{cccccc} 
Polymers & $\begin{array}{c}\mathrm{f}_{\mathrm{IA}}{ }^{\mathrm{a})} \\
(\mathrm{wt} \%)\end{array}$ & $\begin{array}{c}\mathrm{f}_{\mathrm{CA}}{ }^{\mathrm{b})} \\
(\mathrm{wt} \%)\end{array}$ & $\begin{array}{c}\left.\mathrm{f}_{\mathrm{IA}, \mathrm{NMR}}{ }^{\mathrm{c}}\right) \\
(\mathrm{wt} \%)\end{array}$ & $\begin{array}{c}M_{v} \\
(\mathrm{~g} / \mathrm{mol})\end{array}$ & $\mathrm{E}_{\mathrm{s}}^{\mathrm{d})}$ \\
\hline PAN & - & - & - & 245471 & 1.80 \\
Poly(AN-IA) & 2 & - & 4.2 & 240536 & 7.17 \\
Poly(AN-CA) & - & 2 & - & 333426 & 2.12 \\
Poly(AN-IA-CA) & 1 & 1 & 4.7 & 291072 & 3.60 \\
\hline
\end{tabular}

PAN: polyacrylonitrile, AN: acrylonitrile, IA: itaconic acid, CA: crotonic acid, NMR: nuclear magnetic resonance.

${ }^{a)} f_{I A}=[I A] \times 100 /[I A+A N]$ in feed.

${ }^{\text {b) }} f_{C A}=\{[C A+A N]-[A N]\} \times 100 /[C A+A N]$ in feed.

${ }^{c)} f_{I_{A}}=\{[I A+A N]-[A N]\} \times 100 /[I A+A N]$ in polymer calculated from NMR.

${ }^{\text {d) }} E_{s}=A_{1595 \mathrm{~cm}-1} / A_{2245 \mathrm{~cm}-1}$ in polymer calculated from Fourier transform infrared spectroscopy. 


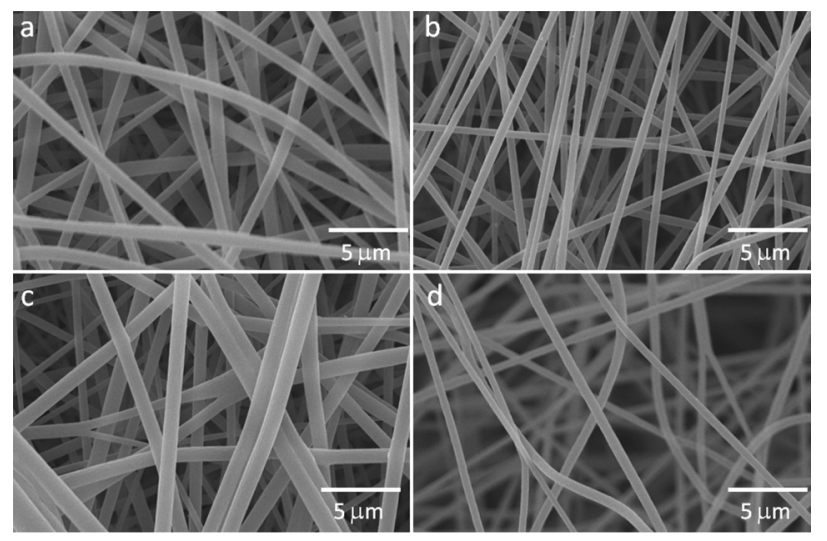

(a)

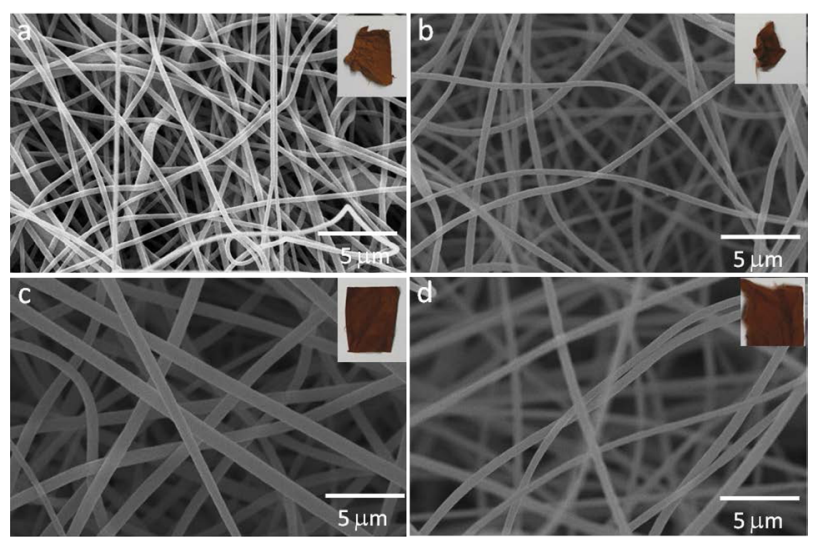

(b)

Fig. 1. Scanning electron microscope images of electrospun polyacrylonitrile homopolymer (a), poly(AN-IA) (b), poly(AN-CA) (c), poly(AN-IA-CA) (d) copolymer nanofibers before (A) and after (B) stabilization at $280^{\circ} \mathrm{C}$ for $1 \mathrm{~h}$. The inset in Fig. $3 \mathrm{~b}$ shows real pictures of corresponding stabilized nanofibers. AN: acrylonitrile, IA: itaconic acid, CA: crotonic acid.

lar, the diameter of the poly(AN-CA) copolymer nanofibers was larger than those of the others; this was probably due to the higher molecular weight of the poly(AN-CA) copolymer (Table 1). After stabilization, the appearance of the fibers became deep brown; the diameter of the fibers did not significantly change. Interestingly, as can be seen in the inset of Fig. 1b, the PAN copolymers that included the CA comonomer showed outstanding dimensional stability (lower volume fraction) of nanofiber mats even after stabilization at higher temperature.

Fig. 2 shows the FT-IR spectra of the PAN homopolymer and its copolymers before Fig. 2(A) and after Fig. 2(B) heating at $280^{\circ} \mathrm{C}$ for $1 \mathrm{~h}$. As can be seen in Fig. 2a, the band at $2245 \mathrm{~cm}^{-1}$ was due to a characteristic stretching vibration of $\mathrm{C} \equiv \mathrm{N}$ in the synthesized PAN homopolymer. For the case of the PAN copolymers (b, c, d in Fig. 2(B)), the $\mathrm{C}=\mathrm{O}$ group was observed at $1738 \mathrm{~cm}^{-1}$, due to an incorporated comonomer containing carboxylic acid groups. Importantly, after heat treatment, the 1738 $\mathrm{cm}^{-1}$ band of the $\mathrm{C}=\mathrm{O}$ group disappeared, and the $\mathrm{C} \equiv \mathrm{N}$ bond at $2245 \mathrm{~cm}^{-1}$ decreased significantly, indicating that a cyclization reaction had occurred [13]. Moreover, a new peak at $1589 \mathrm{~cm}^{-1}$ appeared due to the $\mathrm{C}=\mathrm{C}, \mathrm{C}=\mathrm{N}$ bond, which suggests the forma-
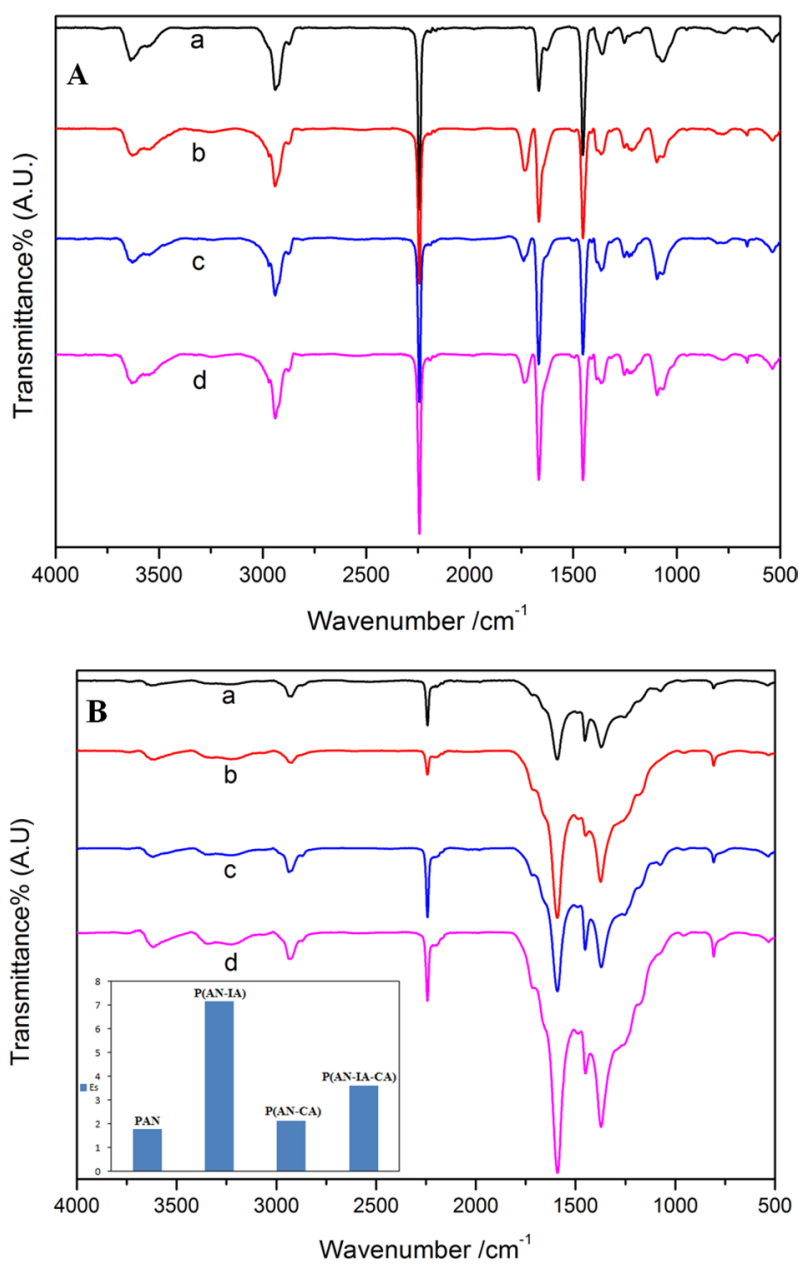

Fig. 2. Fourier transform infrared spectra of electrospun polyacrylonitrile (PAN) homopolymer (a), poly(AN-IA) (b), poly(AN-CA) (c), poly(AN-IACA) (d) copolymer nanofibers before (A) and after (B) stabilization at $280^{\circ} \mathrm{C}$ for $1 \mathrm{~h}$. The inset in Fig. $2 \mathrm{~b}$ shows the Es values of PAN homopolymer and its copolymers. AN: acrylonitrile, IA: itaconic acid, CA: crotonic acid.

tion of a ladder structure [14]. As the stabilization proceeded, the $2245 \mathrm{~cm}^{-1}$ band of the nitrile groups decreased in intensity. The $1595 \mathrm{~cm}^{-1}$ band continued to increase, showing an enhanced stabilization reaction [15]. Here, the $\mathrm{E}_{\mathrm{s}}$ parameter was defined to evaluate the extent of stabilization:

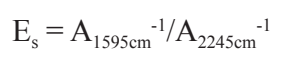

where $\mathrm{A}$ is the absorbance, defined as $\mathrm{A}=\log \left(\mathrm{T}_{\mathrm{o}} / \mathrm{T}\right) ; \mathrm{T}_{\mathrm{o}}$ and $\mathrm{T}$ are the transmittances at baseline and maximum, respectively. In accordance with Lambert-Beer's law: $\mathrm{A}=\mathrm{abc}$, where $\mathrm{a}$ is the molar absorption coefficient, $\mathrm{b}$ is the thickness of the film $(\mathrm{cm})$, and $\mathrm{c}$ is the mole concentration $(\mathrm{mol} / \mathrm{cm})$. Since the absorbances

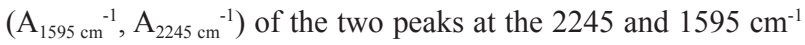
bands were determined using the same fiber, namely, a fiber with the same value of $b$, the ratio of the absorbance of these two bands is approximately equal to the ratio of the content of the generated $\mathrm{C}=\mathrm{N}$ groups to the residual $\mathrm{C} \equiv \mathrm{N}$ groups. The inset in Fig. $2 b$ shows the $\mathrm{E}_{\mathrm{s}}$ values of the PAN homopolymer and 


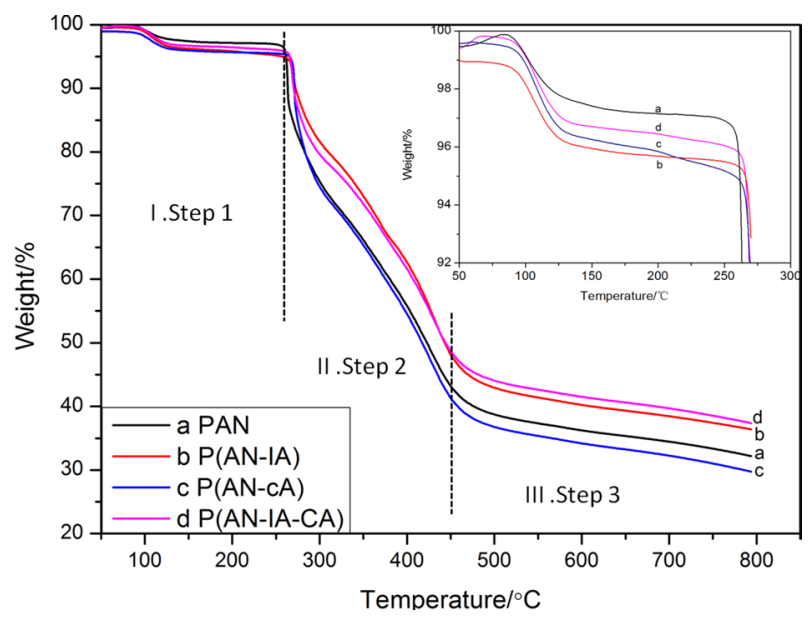

Fig. 3. Thermogravimetric analysis (TGA) curves of electrospun polyacrylonitrile homopolymer (a), poly(AN-IA) (b), poly(AN-CA) (c), poly(AN-IACA) (d) copolymer nanofibers before (A) and after (B) stabilization at $280^{\circ} \mathrm{C}$ for $1 \mathrm{~h}$. The inset shows the magnified view of the TGA curves at the first step during heating. AN: acrylonitrile, IA: itaconic acid, CA: crotonic acid.

of its copolymers with different weight ratios of CA and IA comonomer contents. The $\mathrm{E}_{\mathrm{s}}$ value of the PAN copolymers was higher than that of the PAN homopolymer. That is, the poly(ANIA) copolymer had an Es value higher than that of the other copolymers. Moreover, the $\mathrm{E}_{\mathrm{s}}$ value of the poly(AN-IA-CA) copolymer was somewhat larger than that of the poly(AN-CA) copolymer. This indicates that the CA comonomer can retard/control the extent of stabilization of PAN; this is in contrast to the case of the IA comonomer, which accelerates the stabilization. It is most important to control the rates of physical and chemical changes due to the presence during the stabilization of a variety of exothermic chemical reactions, including cyclization, dehydrogenation, oxidation, crosslinking, and fragmentation. Among these processes, the cyclization reactions, which convert the polymer chains into an infusible stable ladder structure, were of highest importance, playing a key role in the preparation of the carbon fibers [16].

In order to investigate the thermal degradation behaviors of the synthesized PAN homopolymer and its copolymers, TGA analysis was carried out. Fig. 3 shows the TGA results for the synthesized PAN homopolymer, and for the poly(ANIA), poly(AN-CA), poly(AN-IA-CA) copolymers. TGA data can be separated into three main steps based on the degree of weight loss. The first step was prior to $260^{\circ} \mathrm{C}$, during which the weight loss was tiny and cyclization occurred. Clearly, the PAN copolymers had higher levels of weight loss than did PAN homopolymer. It was apparent that IA and CA as acidic comonomers accelerated the extent of cyclization during the stabilization, which also led to the lower $\mathrm{E}_{\mathrm{s}}$ value (inset of Fig. 2b). The second step was around $260^{\circ} \mathrm{C}-450^{\circ} \mathrm{C}$, during which the curves exhibited a sharp decline, mostly due to dehydrogenation $[16,17]$. After the formation of a stable ladder structure via cyclization, the PAN homopolymer and poly(AN-CA) copolymer showed higher levels of decomposition. This suggests that the greater cyclization for the case of the poly(AN-IA) copolymer resulted in greater thermal stability. However, the poly(AN-IA$\mathrm{CA})$ copolymer with the $\mathrm{CA}$ of $1.0 \mathrm{wt} \%$ showed a thermal stability similar to that of the poly(AN-IA) copolymer, indicating that the CA comonomer improved the thermal stability during the second step (Fig. 2). During the third step, above $450^{\circ} \mathrm{C}$, the weight loss tended to be stable. Furthermore, the poly(ANIA) and poly(AN-IA-CA) copolymers exhibited higher residues at $800^{\circ} \mathrm{C}$ than did the PAN homopolymer or the poly(AN-CA) copolymer.

The typical XRD pattern of the as-spun PAN homopolymer showed a strong peak at $2 \theta=17^{\circ}$; its copolymer nanofibers showed relatively weak peaks around $2 \theta=24^{\circ}$ (for the PAN homopolymer) and $29^{\circ}$ (for the PAN copolymers); these last two peaks were assigned to the (100) and (010) crystalline planes of the pseudohexagonal lattice. Compared to the PAN homopolymer, the peak at $2 \theta=17^{\circ}$ in the case of the PAN copolymers was relatively weak. This indicates that there were fewer intermolecular nitrile group pairings in the PAN copolymers because of the random/irregular arrangement of the molecular chains [14]. After stabilization of the poly(AN-IA) copolymer fibers, the intensity of the main peak at $2 \theta=17^{\circ}$ nearly disappeared (data not shown). Similar observations have been reported in other studies [14]. On the other hand, poly(AN-CA) and poly(AN-IA$\mathrm{CA})$ copolymer fibers still showed weak diffraction, suggesting that the incorporated CA comonomers were able to sustain the crystal structure of the polymers.

Scheme 1 shows the cyclization in the poly(AN-IA-CA) copolymer, initiated through an ionic mechanism. It is widely accepted that the cyclization of nitrile groups in PAN can be initiated only at a higher temperature through a free radical mechanism, while the cyclization in poly(AN-IA) copolymer can be initiated by the carboxylic groups of IA units at a lower temperature through an ionic mechanism [16]. As can be seen in Scheme 1, the hydroxyl oxygen of $-\mathrm{COOH}$ in the IA or CA units makes a nucleophilic attack on the carbon atom of an adjacent nitrile group and induces it to cycle. Such an oxygen uptake
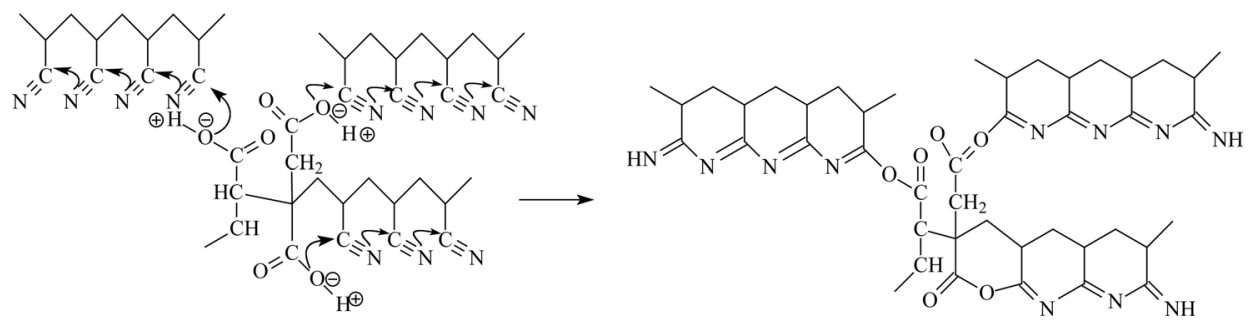

Scheme 1. Plausible cyclization mechanism in poly(AN-IA-CA) copolymer as a model compound. AN: acrylonitrile, IA: itaconic acid, CA: crotonic acid. 
reaction can be confirmed by FT-IR analysis (Fig. 1b), which shows two shoulders at 1718 and $1660 \mathrm{~cm}^{-1}$, which were due to the oxygen uptake reactions. The first shoulder was assigned to $\mathrm{C}=\mathrm{O}$ stretching vibrations of a free ketone; the second was assigned to stretching vibrations of a conjugated ketone [16,17]. In this work, the major difference between IA and CA when used as comonomers containing acid groups is the number of carboxylic groups, which provides more opportunities to induce the nitrile group to cyclize following the ionic mechanism. Therefore, it was expected that the copolymer containing IA experienced more cyclization than did the copolymer containing CA, promoting the extent of stabilization.

\section{Conclusions}

New precursors, poly(AN-CA) and poly(AN-IA-CA) copolymers, for the preparation of carbon fibers, were synthesized via a conventional free-radical polymerization. The synthesized PAN copolymers, which contain CA, showed higher $M_{v}$ values than those of the PAN copolymers; they also showed outstanding dimensional stability of nanofibers at higher temperature and hence may be useful in improving the dimensional stability of polymer composites during manufacturing processes. As a result, it was determined that the CA comonomer can retard/control the stabilization rate of PAN, in contrast to the case of the IA comonomer, which accelerates the stabilization process. IA and $\mathrm{CA}$ as acidic comonomers accelerate the extent of cyclization during stabilization, which also corresponds to lower $\mathrm{E}_{\mathrm{s}}$ values.

\section{Acknowledgments}

This work was supported by a National Research Foundation of Korea (NRF) Grant funded by the Korean Government (MSIP) (No. 2014R1A4A1008140) and by the "Robot industrial cluster construction program" through the Ministry of Trade, Industry \& Energy (MOTIE) and the Korea Institute for Advancement of Technology (KIAT), and partly by a grant (2013HAA22) from the Jeonbuk Research \& Development Program funded by Jeonbuk Province.

\section{References}

[1] Chand S. Carbon fibers for composites. J Mater Sci, 35, 1303 (2000). http://dx.doi.org/10.1023/A:1004780301489.

[2] Mochida I, Yoon SH, Takano N, Fortin F, Korai Y, Yokogawa $\mathrm{K}$. Microstructure of mesophase pitch-based carbon fiber and its control. Carbon, 34, 941 (1996). http://dx.doi.org/10.1016/00086223(95)00172-7.

[3] Li W, Long D, Miyawaki J, Qiao W, Ling L, Mochida I, Yoon SH. Structural features of polyacrylonitrile-based carbon fibers. J Mater Sci, 47, 919 (2012). http://dx.doi.org/10.1007/s10853-011$5872-2$.

[4] Lv MY, Ge HY, Chen J. Study on the chemical structure and skin- core structure of polyacrylonitrile-based fibers during stabilization. J Polym Res, 16, 513 (2009). http://dx.doi.org/10.1007/s10965008-9254-7.

[5] Zhang WX, Wang YZ, Sun CF. Characterization on oxidative stabilization of polyacrylonitrile nanofibers prepared by electrospinning. J Polym Res, 14, 467 (2007). http://dx.doi.org/10.1007/ s10965-007-9130-x.

[6] Bahl OP, Manocha LM. Characterization of oxidised pan fibres. Carbon, 12, 417 (1974). http://dx.doi.org/10.1016/00086223(74)90007-4.

[7] Wangxi Z, Jie L, Gang W. Evolution of structure and properties of PAN precursors during their conversion to carbon fibers. Carbon, 41, 2805 (2003). http://dx.doi.org/10.1016/S0008-6223(03)00391-9.

[8] Ko YI, Lee Y, Devarayan K, Kim BS, Hayashi T, Kim IS. Annealing effects on mechanical properties and shape memory behaviors of silicone-coated elastomeric polycaprolactone nanofiber filaments. Mater Lett, 131, 128 (2014). http://dx.doi.org/10.1016/j. matlet.2014.05.184.

[9] Wu M, Wang Q, Li K, Wu Y, Liu H. Optimization of stabilization conditions for electrospun polyacrylonitrile nanofibers. Polym De$\operatorname{grad}$ Stab, 97, 1511 (2012). http://dx.doi.org/10.1016/j.polymdegradstab.2012.05.001.

[10] Cleland RL, Stockmayer WH. An intrinsic viscosity-molecular weight relation for polyacrylonitrile. J Polym Sci, 17, 473 (1955). http://dx.doi.org/10.1002/pol.1955.120178602.

[11] Liu JJ, Ge H, Wang CG. Modification of polyacrylonitrile precursors for carbon fiber via copolymerization of acrylonitrile with ammonium itaconate. J Appl Polym Sci, 102, 2175 (2006). http:// dx.doi.org/10.1002/app.24256.

[12] Bhanu VA, Rangarajan P, Wiles K, Bortner M, Sankarpandian M, Godshall D, Glass TE, Banthia AK, Yang J, Wilkes G, Baird D, McGrath JE. Synthesis and characterization of acrylonitrile methyl acrylate statistical copolymers as melt processable carbon fiber precursors. Polymer, 43, 4841 (2002). http://dx.doi.org/10.1016/ S0032-3861(02)00330-0.

[13] Rahaman MSA, Ismail AF, Mustafa A. A review of heat treatment on polyacrylonitrile fiber. Polym Degrad Stab, 92, 1421 (2007). http://dx.doi.org/10.1016/j.polymdegradstab.2007.03.023.

[14] Devasia R, Nair CPR, Sadhana R, Babu NS, Ninan KN. Fourier transform infrared and wide-angle $\mathrm{X}$-ray diffraction studies of the thermal cyclization reactions of high-molar-mass poly(acrylonitrile-co-itaconic acid). J Appl Polym Sci, 100, 3055 (2006). http://dx.doi.org/10.1002/app.23705.

[15] Ju A, Zhang K, Luo M, Ge M. Poly(acrylonitrile-co-3-ammoniumcarboxylate-3-butenoic acid methyl ester): a better carbon fiber precursor than acrylonitrile terpolymer. J Polym Res, 21, 1 (2014). http://dx.doi.org/10.1007/s10965-014-0395-6.

[16] Ouyang Q, Cheng L, Wang H, Li K. Mechanism and kinetics of the stabilization reactions of itaconic acid-modified polyacrylonitrile. Polym Degrad Stab, 93, 1415 (2008). http://dx.doi.org/10.1016/j. polymdegradstab.2008.05.021.

[17] Shimada I, Takahagi T, Fukuhara M, Morita K, Ishitani A. FT-IR study of the stabilization reaction of polyacrylonitrile in the production of carbon fibers. J Polym Sci A, 24, 1989 (1986). http:// dx.doi.org/10.1002/pola.1986.080240819. 